\title{
What is physiological psychology?
}

\author{
PETER M. MILNER and NORMAN M. WHITE \\ McGill University, Montreal, Quebec, Canada
}

(Invited Article)

\begin{abstract}
We examine the philosophy underlying the discipline of physiological psychology and give a brief review of its phrenological and neurological precursors. Psychology is often regarded as less "scientific" than other life sciences; the reasons for this are analyzed. We argue that behavioral measures are as inherently reliable as those of the other life sciences. Physiological psychology is the attempt to forge reductionist links between behavior and the physiology of the behaving system, but it differs from examples of reductionism in most other sciences. Most behavioral observations have traditionally been explained by nonmaterial factors, not by the nervous sytem, and neurophysiology and neurochemistry have developed largely independently of the behavior they should explain. The reasons for this phenomenon and the role of physiological psychology in correcting it are discussed.
\end{abstract}

Physiological psychology stems from an ancient philosophical position that people (and other animals) behave as they do because of their physical constitution. Anaxagoras, a Greek philosopher who lived about 2,500 years ago, is reputed to have held such a view, and there have been many other advocates through the centuries. The hypothesis has also aroused opposition, especially from established religions, because it leaves no role for an immaterial anima, or spirit, in the determination of behavior. In fact, in certain periods and places the opposition has been so powerful that it has required courage, not to say foolhardiness, to proclaim Anaxagoran ideas, making it difficult to estimate just how widely they may have been held in private.

The history of science provides many examples of mysteries' and myths' being superseded by logical inference from universal axioms. It may be more entertaining to believe that the sun and moon are moved through the heavens by supernatural beings, but the explanation in terms of gravitational force has the advantage that the same laws of motion can be used to determine the trajectories of other objects, such as apples, projectiles, or space vehicles.

In biology, the difference between animate and inanimate objects still has not entirely lost its aura of mystery, although it is no longer respectable in scientific circles to attribute the difference to some vital essence. As recently as the last century it was widely believed that certain substances (organic chemicals) could not be synthesized outside the bodies of living organisms. This belief was overturned in 1828 by Wöhler, who prepared urea from inorganic chemicals in his laboratory. This set the

We would like to thank our colleagues, Keith Franklin for valuable discussions, and Richard Hirsh and John Macnamara for their comments on an earlier version of the manuscript. Address correspondence to Peter M. Milner, Department of Psychology, McGill University, 1205 Dr. Penfield Avenue, Montreal, Quebec H3A 1B1, Canada. stage for the field of biochemistry, which has gone a long way toward eliminating the mysteries of life processes.

In the mental sphere, mysteries still abound. Introspection reveals a "self" that most of us have difficulty identifying with any physical process in the brain. A real effort is required to think of our own social behavior, or even that of animals, as being due solely to the activity of the nervous system, a view demanded by a rigorous application of physiological psychology. Few people, even life scientists, willingly give up their souls or their free wills. Fortunately, perhaps, human thought processes are not entirely logical, and it is possible for incompatible ideas to coexist in watertight compartments. Perhaps the earliest instance of this phenomenon with regard to our understanding of the control of behavior occurred in the case of phrenology.

Phrenology was a forerunner of physiological psychology. It originated with Gall (1810), an anatomist, who proposed that the extent to which various mental abilities and personality traits were manifested depended on the development of particular parts of the brain, and that differences in regional brain development were reflected in the shape of the skull. Thus great numbers of people, most of whom presumably believed that their behavior was determined by an immaterial (and immortal) soul, had their skull bumps read by phrenologists in the early years of the last century.

Unfortunately, neither the anatomical nor the psychological tools were available at the time to test the hypothesis of phrenology properly. The shape of the skull was a poor indicator of the relative sizes of different brain regions, and anecdotal or subjective reports were unsatisfactory grounds for assessing mental faculties. For this reason (and because many charlatans made a good thing out of its popularity), phrenology soon acquired a bad reputation among scientists, although some took the basic idea that mental functions were localized in the brain seriously enough to try to test it more rigorously. Flourens 
(1823), in one of the earliest physiological psychology experiments, attempted to discover the roles of different brain regions in the behavior of animals. His experiments provided little support for the theory of localization of function, although he did discover that lesions of the occipital part of the brain caused loss of vision in rabbits and dogs.

Flourens's (1823) research was also the first to demonstrate the need for the participation of psychologists in this type of experiment: Flourens used only the most primitive methods for assessing the abilities of his subjects. Unfortunately, the science of animal psychology was still in the future; it would be many years before psychology emerged from its philosophical cocoon to wrestle with the task of measuring the subtle aspects of intelligence and personality that elude casual observation. We now know that very specific changes in behavior result from the localized brain lesions that Flourens thought to have no effect.

Neurology was a more solid and reputable forerunner of physiological psychology than was phrenology. By the end of the 19th century, anatomists and neurologists had determined the sensory and motor connections of the mammalian brain with reasonable accuracy and a good deal had been learned about the mechanism of spinal reflexes. Gall's (1810) ideas about localization of function continued to be investigated. Patients with brain disease were tested to determine the extent to which mental functions could be localized in the brain, and the results were frequently the subject of heated controversy. Hughlings Jackson's (1884) hierarchical model of the influence of different levels of the nervous system on each other was another neurological theory with important implications for understanding the brain-behavior relationship.

Psychologists showed some interest in these findings. William James's Principles of Psychology (1890), for example, opens with two chapters on the brain, but most of the speculation as well as the research into the relationship between the nervous system and behavior was being done by neurologists.

It is not surprising that neurologists pioneered this field, because it is through the abnormalities of behavior that accompany neural dysfunction that the relationships between behavior and the nervous system are most conspicuously revealed. Neurological diagnosis was reasonably successful because the behavior changes on which it was based were conspicuous enough not to require complex measuring techniques. Early attempts to relate mental abilities to brain function were unsuccessful in part because of the difficulty of measuring mental abilities. Such measurements are as difficult to perform properly as any other scientific measurements, if not more so.

Neurological training is more than adequate to enable a researcher to detect abnormalities of functions such as walking, sensory acuity, or eating, or even gross disturbances of speaking or learning; but for investigating more detailed or subtle behavior, psychological sophistication is necessary. For instance, the initial findings about the role of the hypothalamus in eating were made by neurologists (e.g., Anand \& Brobeck, 1951; Fröhlich, 1901; Hetherington \& Ranson, 1940), but the kind of behavioral analysis that only psychologists were likely to think of, or were equipped to carry out (e.g., Miller, Bailey, \& Stevenson, 1950; Teitelbaum, 1955, 1957), was required to begin the process of unraveling the very complex contributions of the hypothalamus to feeding. Similarly, amnesia resulting from brain damage was reported by neurologists (Bechterev, 1900; Glees \& Griffith, 1952; Korsakoff, 1889), but they made little contribution to our understanding of memory. It was not until amnesic patients were studied by psychologists (e.g., Milner, 1959; Milner \& Teuber, 1968; Zangwill, 1950) that more precise analyses of the behavioral effects of brain damage were made.

Neurologists, as medical practitioners, are more interested in diagnosis and treatment of abnormal behavior than in understanding the mechanisms of normal behavior; thus neurophysiology evolved as the experimental branch of their discipline. This evolution appears to have been incomplete, however, as the neurophysiologists concentrated their efforts entirely on the nervous system, losing sight of its functional outcome in behavior. Why did concern with the behavioral output of the nervous system fail to make the transition from neurology to neurophysiology? One possible explanation involves priority and prestige. Physiology was seen as more basic, and therefore somehow more scientific. The development of the vacuum tube permitted accurate measurement of the electrical properties of the nervous system in established scientific units such as volts and coulombs. The measurement of behavior, on the other hand, required the discovery and validation of a whole new set of units. This led to the impression that the measurement of behavior is somehow less precise and therefore less reliable than the measurement of other biological variables.

The association of neurophysiology with medicine also provides the field with more prestige and money than are accorded psychology, which is associated with the more traditional basic and social sciences. Finally, the philosophical objection to explaining behavior in mechanistic terms must be recalled. In a medical setting, where there is apt to be much rhapsodizing about the artistic nature of medical science, the basic scientist may find it more congenial to restrict her or his theoretical outlook. Physicians are willing to accept physiological explanations for disease, but their own view of themselves and the problems they face in their profession makes it much more difficult for them to accept physiological explanations with implications for all of normal behavior.

So bringing neurophysiological and behavioral data together was left to the psychologists. Around the turn of the century, many psychologists (James has been mentioned) were willing to apply the neural findings of neurologists and neurophysiologists to their own theories of 
mental function. It is worth noting, however, that few if any psychologists adopted the experimental methods of the physiologists or collaborated with them.

Karl Lashley may have been the first person with primarily psychological training to become actively engaged in the study of brain mechanisms in learning and other mental functions; certainly he is the best known of the pioneers in the field. In 1917 Lashley worked with the experimental neurologist S. I. Franz, who was using the technique of cortical ablation to study the localization of learning. Lashley continued these studies on his own during the $1920 \mathrm{~s}$, using rats as subjects. Thirty years later Lashley and a few of his students were still responsible for most of the experiments actually done by psychologists that were cited in textbooks of physiological psychology.

A major reason for this is clear; at about the time Lashley started his career, his former supervisor, J. B. Watson, fired the first shots of the behaviorist revolution. Behaviorism rapidly became the dominant force in American psychology, and many influential adherents were antagonistic to physiological interpretations of behavior. Mainstream psychologists snubbed the nervous system for the next 40 years.

It may seem strange that behaviorism, a movement dedicated to the demystification of behavior and the eradication of all traces of mentalism from psychology, should firmly turn its back on attempts to explain behavior in terms of the activity of material objects like neurons. A number of reasons for this phenomenon can be identified. One factor is that psychology had been separated from philosophy for only about a generation, and many of its leaders identified more with philosophy than with biology. Reluctance on the part of many psychologists to stray into the unfamiliar territory of the nervous system may have been another factor. Behaviorism provided a methodology that yielded straightforward data (barpresses, running speed) and relieved those who collected these data from the burden of having to consider their relation to a parallel set of physiological variables. Even Lashley was not able to produce any convincing evidence of the value of physiological psychology for the understanding of learning. In fact, he despaired of even locating where in the brain learning changes might take place. Together with the rejection of the philosophical implications of physiological psychology, these prevailing attitudes inhibited the development of the field for a time.

Behaviorist dogma held that the relations between environmental events and behavior could be investigated most efficiently and expressed most parsimoniously by using variables and hypothetical constructs that were derived purely from behavioral observations, without reference to physiological preconceptions. Of course this was an ideal that even the most zealous behaviorist could hardly live up to, as Hebb (1951) and others pointed out. The flaw in the behaviorist stance is that one can go only so far in isolation from surrounding disciplines. Reductionist explanations cannot be avoided for long in science. If there were no nervous system, psychologists would have to invent one, and then research would determine whether or not the invention was along the right lines.

It is generally agreed that $\mathrm{D}$. $\mathrm{O}$. Hebb, in The Organization of Behavior (1949), broke through the intellectual barriers erected by the physiologists on the one side and the behaviorists on the other to provide the first example of modern physiological psychology. It is instructive to examine how behavioral and physiological variables interact in his writings.

As we have mentioned, when the psychologists began to construct theories to explain the phenomena revealed by their experiments, most of them looked to neurology and physiology for cues. Hebb (1949) wrote his book as if he were constructing his theories from neural data, when in fact nothing could have been further from the truth. Rather, Hebb took the available behavioral data and searched for neurological mechanisms that could explain them. The Hebb synapse is an example of a physiological postulate based on behavioral data. Almost 40 years after it was proposed, we are still looking for the neurological basis of the behavioral phenomena explained by this postulate. In The Organization of Behavior, Hebb gives the impression that he formulated the notion of the reverberatory circuit after reading about Lorente de Nó's (1938) neural loops. In fact, of course, he must have known before reading Lorente de Nó that there had to be a storage mechanism that, however short-term it may have been in behavioral terms, was very long-term in the neural context. The neural loops suggested a neural mechanism that could meet this behavioral requirement.

We see in this analysis that reductionism in science does not always involve assembling facts discovered at a lower level to construct models that account for observations at a higher level. Hebb (1949) wrote as if he had constructed his theory in this way, but in fact it is obvious that he did quite the opposite: he started with available behavioral data and searched for neurological mechanisms that could explain them. If physiologists had not yet discovered the mechanisms he needed, he postulated them.

In general, scientific knowledge is systematized through reductionist links. The data of chemical experiments are explained in terms of the physical properties of atoms, atomic reactions are explained in terms of forces between hypothetical subatomic particles, and so on. Physicists did not create this chain of explanation by starting with the most elementary particles of matter and working their way up to atomic particles, molecules, and so forth; in fact, the explanation of matter proceeded in exactly the opposite direction. Similarly, it is psychology that should provide the framework for organizing and understanding the findings of physiology.

Physiology is unusual in having originated independently of the philosophical and behavioral questions that it is now being called upon to answer. A probable reason for this is that until recently most people have been satisfied with explanations of behavior in terms of the mind, rather than of the nervous system. Now that the link between behavior and the nervous system is more widely accepted, however, it is time that the role of psychology 
as a source of neurophysiological and neurochemical hypotheses is recognized.

There is often a tendency for individuals who are trained as psychologists to regard behavioral measures as in some way less scientific and less important than physiological or other biological measures; we can hardly blame other neuroscientists if they adopt a similar belief. Ironically, this impression seems to have stemmed at least in part from the psychologists' use of statistics to interpret their data. Because they relate to the same biological systems, neurophysiological, neurochemical, and behavioral measurements are all subject to the same sources of variability. Some life scientists appear to confuse the type of data collected in chemistry, which are based on relatively invariant inorganic substances, with those collected in biochemistry, which are based on living systems with inherent variability. It is noteworthy that psychologists have traditionally been more sophisticated than other life scientists in understanding and dealing with this variability in their data through the use of modern statistics. Physiologists, pharmacologists, and others often have a tendency to deal with variability by ignoring it. For example, their failure to analyze their data statistically caused Hubel and Wiesel to miss a whole category of visual cortex neurons with nonoriented fields (Livingstone \& Hubel, 1984) for many years. Rather than accepting the fact that all data in the life sciences are subject to variability and require this type of analysis, neurophysiologists, neurochemists, and others have often been disparaging of behavioral data because statistics are required to understand it.

Neuroscientists must learn to recognize the primacy and power of behavioral data in relation to understanding how the nervous system works. The first question a scientist would ask if confronted with a watch for the first time would be "What does it do?" Only a child would start by dismantling it into its component springs and gears (or nowadays, its even less informative chips and displays). Similarly, anyone who starts with data from experiments on neurons and claims to build a model of, for example, learning, or the control of eating, is surely under a serious delusion.

Psychological data should, and do, influence the way we think about the nervous system: Consider how often new anatomical connections are discovered after behavioral data have shown them to be functionally necessary. The way to ensure that the interaction between the neighboring fields is as easy and fruitful as possible is for psychologists to think in terms of neural constructs and to consider the properties hypothetical neurons must have in order to explain their results.

On the other side of the physiological-behavioral divide, there are still many psychologists who believe that neural models are too constricting and that psychological phenomena should be explained in terms of a nonneural set of hypothetical constructs. Such thinking reflects, we believe, an exaggerated respect for neurophysiology. Psychologists should have impressed upon them that the nervous system is not well understood and imposes few restrictions on their imaginations, especially as regards those properties most likely to interest psychologists. If a psychological observation appears to contradict a physiological belief, then that belief is probably wrong and should be confronted, not bypassed. Hebb was criticized for inventing neural constructs, such as the cell assembly, that have no neurological standing. But such constructs have the advantage of imposing a degree of uniformity on psychological models, so that advances in one area can easily be extended to other areas. Moreover, whereas nonneural hypothetical constructs are accessible only through further psychological experiments, a neural model, in theory at least, has implications that can be tested independently by physiological experiments.

These are the ways in which modern physiological psychology assumes a pivotal role in our understanding of the relationship between behavior and the nervous system. The physiological psychologist is not content merely to scavenge the physiological literature for useful scraps. Rather, these behavioral scientists make extensive use of physiological methods in their research. At first these involved mainly cortical lesions, then stereotaxic lesions and stimulation. Now the whole armamentarium of neuroscience, including techniques of neuroanatomy, neuropharmacology, and neurophysiology, is commonly used by physiological psychologists to map the relationship between behavior and the nervous system.

Physiological psychology, then, is the simultaneous study of the brain and of the behavior it produces. But we would be naive if we failed to recognize that, unlike other scientific variables, behavior has a personal dimension. It is something we all observe every day of our lives, and about which we form more or less hazy, but strongly held, ideas before even learning to spell the word psychology. The organization of behavior that each of us discerns in our prepsychological state may or may not correspond to the way in which behavior is actually organized by the brain.

The forms of behavioral organization conceived of in purely behavioral experiments suffer from the same flaw. Since these experiments do not take brain function into account, these concepts do not necessarily correspond to the way in which behavior is organized by the brain.

The basic tenet of physiological psychology is that behavior is organized and controlled by the brain; the central question we seek to answer is how does the brain accomplish this control and organization. To answer this question, we must approach the study of both the nervous system and behavior in an objective manner. As it is extremely unlikely that the observation of either the brain or behavior alone, either informally or in the laboratory, will reveal how the two are related, the two must be manipulated simultaneously. As we attempted to show in our analysis of Hebb's $(1949,1951)$ writings, behavioral analysis informs us about brain function, and at the same time data about brain function shape and limit our behavioral analyses. Thus the corresponding units of brain function and behavior can be identified.

In the field of physiological psychology, we must put aside our preconceptions, whether they are derived from 
our own informal observations or from purely behavioral experiments. Behavior must be viewed abstractly as a series of objective events that can be combined and organized in different and unexpected ways. It is this requirement that makes behavioral analysis different from, and more difficult than, the more conventional data collection procedures used in the other life sciences. This requirement is one reason some psychologists leave the field in favor of areas that produce less complex and more easily controlled types of scientific data. But it is also what makes physiological psychology the most intellectually challenging, and therefore the most interesting, branch of the neurosciences.

\section{REFERENCES}

ANAND, B. K., \& BRoBeck, J. R. (1951). Hypothalamic control of food intake in rats and cats. Yale Journal of Biology \& Medicine, 24, 123-140.

BeChTEREV, W. voN (1900). Demonstration eines Gehirns mit Zerstörung der vorderer und innerer Theile der Hirnrinde beider Schläfenlaffen. Neurologisches Zentralblatt, 19, 990-991.

Flourens, P. (1823). Recherches physiques sur les propriétés et fonctions du système nerveux dans les animaux vertébrés. Archives Générales de Médecine, 2, 321-374.

FröнцiCH, A. (1901). Ein Fall von Tumor der hypophysis cerebri ohne Akromegalie. Wiener Klinische Rundshau, 15, 883-886, 906-908.

GALL, F. J. (1810). Anatomie et physiologie du système nerveux en générale et du cerveau en particulier, avec des observations sur la possibilité de reconnâitre plusieurs dispositions intellectuelles et morales de lhomme et des animaux par la configuration de leurs têtes. Paris: Schoell.

GleEs, P., \& Griffith, H. B. (1952). Bilateral destruction of the hip- pocarnpus (Cornu Ammonis) in a case of dementia. Monatsschrift fur Psychiatrie und Neurologie, 123, 193-204.

Нввв, D. O. (1949). The organization of behavior. New York: Wiley. HenB, D. O. (1951). The role of neurological ideas in psychology. Journal of Personality, 20, 39-55.

Hetherington, A. W., \& Ranson, S. W. (1940). Hypothalamic lesions and adiposity in the rat. Anatomical Record, 78, 149-172.

JACKSON, H. (1884). The Croonian Lectures on the evolution and dissolution of the nervous system. British Medical Journal, 1, 591-599, 660-663, 703-707.

JAMES, W. (1890). The principles of psychology. New York: Henry Holt.

KorSaKoFF, S. S. (1889). Ftude médico-psychologique sur une forme des maladies de la mémoire. Revue de Philosophie, 28, 501-530.

Livingstone, M. S., \& Hubel, D. H. (1984). Anatomy and physiology of a color system in the primate visual cortex. Journal of Neuroscience, 4, 309-356.

LORENTE DE Nó, R. (1938). Analysis of the activity of the chains of internuncial neurons. Journal of Neurophysiology, 1, 207-244.

Miller, N. E., Bailey, C. J., \& Stevenson, J. A. F. (1950). Decreased "hunger"' but increased food intake resulting from hypothalamic lesions. Science, 112, 256-259.

MiLneR, B. (1959). The memory defect in bilateral hippocampal lesions. Psychiatric Research Reports, 11, 43-52.

Milner, B., \& Teuber, H.-L. (1968). Alterations of perception and memory in man: Reflections on methods. In L. Weiskrantz (Ed.), Analysis of behavioral change (pp. 268-375). New York: Harper.

Teitelbaum, P. (1955). Sensory control of hypothalamic hyperphagia. Journal of Comparative \& Physiological Psychology, 48, 156-163.

Teitelbaum, P. (1957). Random and food-directed activity in hyperphagic and normal rats. Journal of Comparative \& Physiological Psychology, 50, 486-490.

ZANGWILL, O. L. (1950). Amnesia and the generic image. Quarterly Journal of Experimental Psychology, 2, 7-12.

(Manuscript received January 20, 1987; accepted for publication January 26, 1987.) 